\title{
O PÃO NOSSO DE CADA DIA: SOCIALIZAÇÃO DE GÊNERO E RELIGIOSA NA MOBILIZAÇÃO DE COMPETÊNCIAS NO TRABALHO
}

\author{
Naira Pinheiro dos Santos*
}

\section{RESUMO}

A revista Mandrágora tem se dedicado, ao longo da sua existência, a publicar artigos que possibilitam desvelar as entranhas da religião desde uma perspectiva feminista. Tal abordagem tem sua relevância no fato de que possibilita iluminar algo das sociedades nas quais os fenômenos religiosos se fazem presentes, nas mais diversas esferas, seja tomando-as de assalto, seja como simples convidados, seja como algo a esconjurar; ela nos fala de relações sociais de sexo, de classe, de raça/etnia, coloniais, etc. $O$ nosso objetivo através do presente artigo, resultado de pesquisa de doutorado, é o de expor alguns aspectos dessa teia. Trata-se de analisar imbricamentos entre cultura organizacional, gênero e religião. Eles são evidenciados quer pelas representações de gênero e religiosas que atravessam esse contexto, quer pela instrumentalização que tanto as empresas em questão, quanto os/as trabalhadores/as, fazem das competências adquiridas no âmbito da socialização religiosa e de gênero no exercício da atividade profissional.

Palavras-chave: Gênero; religião; cultura organizacional.

\section{OUR DAILY BREAD: GENDER AND RELIGIOUS SOCIALIZATION IN MOBILIZING SKILLS AT WORK}

\section{ABSTRACT}

The Mandrágora journal has been dedicated, throughout its existence, to publishing articles that make it possible to unveil the bowels of religion from a feminist perspective. Such approach has its relevance by the fact that it makes it possible to unveil something about socie-

* Doutora em Ciências da Religião, membro do grupo de pesquisa em gênero e religião Mandrágora/NETMAL e membro da equipe editorial da revista Mandrágora. 
ties in which religious phenomena are present in the most diverse spheres, whether taking them by assault, or as simple guests, or as something to avert; it tells us about social relations of sex, class, race/ethnicity, colonial, etc. Our objective in this article, which is the result of a doctoral research, is to expose some aspects of this web. It aims to analyze the overlaps between organizational culture, gender, and religion. These are evidenced either by the gender and religious representations that traverse this context, as well as by the instrumentalization that both the companies in question and the workers make of the skills acquired in the scope of religious and gender socialization in the exercise of professional activity.

Keywords: Gender; religion; organizational culture.

NUESTRO PAN DE CADA DÍA: LA SOCIALIZACIÓN RELIGIOSA Y DE GÉNERO EN LA MOVILIZACIÓN DE HABILIDADES EN EL TRABAJO

\section{RESUMEN}

La revista Mandrágora se ha dedicado, a lo largo de su existencia, a publicar artículos que permitan desvelar las entrañas de la religión desde una perspectiva feminista. Tal enfoque tiene su relevancia en el hecho de que permite iluminar algo sobre sociedades en las que los fenómenos religiosos están presentes, en los más diversos ámbitos, ya sea tomándolos por asalto, como simples huéspedes o como algo a evitar; nos habla de las relaciones sociales de sexo, clase, raza / etnia, colonial, etc. Nuestro objetivo a través de este artículo, fruto de una investigación doctoral, es exponer algunos aspectos de esta web. Se trata de analizar superposiciones entre cultura organizacional, género y religión. Se evidencian ya sea por las representaciones de género y religiosas que atraviesan este contexto, o por la instrumentalización que tanto las empresas en cuestión como los trabajadores hacen de las competencias adquiridas en el contexto de la socialización religiosa y de género en el ejercicio de la actividad profesional.

Palabras clave: Género; religión; cultura organizacional.

\section{INTRODUÇÃO}

O trabalho é histórica e culturalmente situado, é perpassado por representações sociais as mais diversas, as quais conferem e encontram sentido nas formas dominantes de divisão social num determinado 
contexto. Ele remete à dupla transformação do ser humano e da natureza, que é tanto de ordem material quanto simbólica. Quer se aborde o trabalho do ponto de vista do que representa o ato de trabalhar, do sentido, da forma e conteúdo específicos por meio dos quais ele se realiza, ou do ponto de vista do estatuto que tanto trabalho quanto trabalhador/a ocupam numa determinada sociedade, este sempre engaja relações sociais - ele constitui "uma categoria pertinente de ordenamento e hierarquização" (Michel LALLEMENT, 2007, p. 28). Nesse sentido, tanto o lugar que o trabalho ocupa, quanto o perfil dos sujeitos que a ele têm acesso ou são submetidos, assim como as condições sob as quais ele se realiza, nos falam de hierarquias socialmente estabelecidas. Ele é atravessado e pode definir um jogo de relações sociais conflituosas, nas quais se inserem também as relações de gênero.

O gênero é entendido aqui como uma categoria relacional, ou seja, não como um conceito inerte ou isolado de 'feminino' e 'masculino', ‘homem' e ‘mulher' com características inerentes ou naturais, mas como construção social de relações de dominação a partir das diferenças percebidas entre os corpos (Joan SCOTT, 1990). A emergência da sociedade salarial operou a separação de esferas de trabalho; o gênero opera a naturalização das diferenças sexuais, ocultando, assim, o aspecto arbitrário dos princípios de divisão do mundo social e de divisão social do trabalho. Ele confere significado e legitima relações de poder, constitutivas das relações sociais de sexo. Estas são estruturantes e transversais ao conjunto do campo social (Danièle KERGOAT, 2009). Significa dizer que as relações sociais de sexo estruturam e atravessam também o mundo do trabalho, constituindo o que se convencionou chamar de divisão sexual do trabalho. Sendo "a forma de divisão do trabalho social decorrente das relações sociais de sexo [...] historicamente adaptada a cada sociedade" (Danièle KERGOAT, 2009, p.67), a divisão sexual do trabalho não é fixa ou imutável em suas modalidades, mas transforma-se de acordo com o contexto social e histórico, conforme mudanças da estrutura material, das relações sociais e de novas configurações que se impõem a partir da capacidade de reinterpretação, resistência e negação dos sujeitos e/ou grupos sociais. 
Nas sociedades modernas verifica-se um processo de racionalização do trabalho que, em princípio, implicaria "abstrair este último de um conjunto de espaços e de práticas (as atividades domésticas em primeiro lugar) para melhor modelá-lo segundo os cânones da razão instrumental" (Michel LALLEMENT, 2007, p. 15). Nesse sentido, seria de se supor que os/as trabalhadores/as abstrairiam também a religião no exercício da sua atividade profissional. Com efeito, não obstante o capitalismo, na perspectiva de Max Weber (2000), tenha retirado do protestantismo boa parte de sua força racionalizadora, o imaginário contemporâneo representa as organizações empresariais e a religião como pertencentes a mundos distintos, incompatíveis um com o outro. As primeiras, expressão do mundo moderno, integrariam a esfera pública e o campo da racionalidade por excelência, com todos os adjetivos que lhe são próprios ou adjacentes (masculino, objetivo, eficiente, impessoal, imparcial, etc.), e a segunda, expressão de um mundo arcaico ou tradicional, pertenceria à esfera privada (pessoal/ íntima, subjetiva, "inerentemente" feminina) e se situaria no exterior do campo da racionalidade organizacional, de modo que esta não teria lugar no mundo do trabalho. Contudo, paradoxalmente, o mundo do trabalho não é tão impermeável à religião. Da mesma maneira, se no plano das representações a racionalização do trabalho requereria a abstração das atividades ligadas à esfera doméstica (Michel LALLEMENT, 2007), o que se verifica na prática é, ao mesmo tempo, uma forte permeabilidade e uma invisibilidade ou mesmo negação dessa interpenetração. Para Danièle Kergoat, falar em termos de divisão sexual do trabalho "é articular a descrição do real com uma reflexão sobre os processos pelos quais a sociedade utiliza a diferenciação para hierarquizar essas atividades" (2009, p. 72).

É dessas interações que procuraremos tratar aqui, refletindo sobre formas e implicações da instrumentalização de atributos e/ou competências construídas na socialização de gênero e/ou religiosa, tanto pelas organizações empresariais quanto pelos sujeitos trabalhadores, particularmente no âmbito do setor de serviços. Para tanto, nos utilizaremos de dados de pesquisa de campo empreendida em 2009/2010, 
no Brasil e na França'. Ambas as empresas pesquisadas, Hypermarché e Textile², são de origem francesa com atuação também no Brasil. $\mathrm{O}$ Hypermarché atua no segmento de hipermercados e a unidade pesquisada do grupo Textile atua na indústria têxtil.

Nossa metodologia contemplou a realização de entrevistas junto a trabalhadores/as de diversos níveis funcionais das empresas em questão, bem como o recurso a fontes primárias, tais como dados relativos ao quadro de funcionários e aqueles divulgados no site institucional das empresas. No caso do Hypermarché nos utilizamos também de exemplares da revista de circulação interna da empresa tanto no Brasil quanto na França, além de termos tido a oportunidade de observar murais e cartazes afixados nas áreas internas, destinadas a funcionários/as, das lojas pesquisadas no Brasil. No Brasil, as lojas pesquisadas situam-se na Grande São Paulo e, na França, na região metropolitana de Paris. Abordaremos aqui aqueles aspectos mais diretamente relacionados ao trabalho no setor terciário, de modo que nos referiremos principalmente ao Hypermarché, embora eventualmente destaquemos também alguns dados obtidos junto à Textile. Da mesma maneira, embora no contexto da pesquisa nossa análise tenha contemplado relações sociais de classe, raça/etnia e outras interseccionalidades, a presente análise repousará principalmente sobre as relações de gênero e a socialização religiosa. Não obstante os dados não sejam muito recentes, eles permitem apreender a dinâmica que temos por objetivo apontar neste artigo.

\section{GÊNERO E RELIGIÃO NA CULTURA ORGANIZACIONAL}

"Organizações são componentes indissolúveis da sociedade e da cultura que as abraçam” (Miguel CALDAS, 1997, p. 86). Não obstante o caráter pretensamente neutro e impessoal dos sistemas e métodos organizacionais, estes, ao mesmo tempo em que impregnam a cultura

Trata-se de pesquisa empreendida no contexto de doutorado sanduíche (PPG Ciências da Religião UMESP/GTM - Paris 8) e que contou com apoio da CAPES através dos programas PROSUP e PDEE. A tese foi publicada em: SANTOS, Naira Pinheiro dos. Gênero, religião e cultura organizacional: uma perspectiva comparativa entre Brasil e França. São Paulo: Terceira Via; Universidade Metodista de São Paulo, 2018. (Coleção Religião e Estudos Feministas).

2 Com o objetivo de preservar a identidade das empresas nos utilizamos de nomes fictícios. Adotamos o mesmo procedimento em relação aos nomes dos sujeitos entrevistados. 
da empresa, encontram-se também eles próprios impregnados de valores das sociedades nas quais foram elaborados. Significa dizer que os pressupostos básicos, crenças e valores da cultura de origem e/ou na qual se instala, assim como aqueles implícitos nos sistemas e métodos adotados pela empresa, compõem a sua cultura, o seu conjunto de valores, os quais "contribuem para criar parâmetros de como pensar, sentir e agir" (Alexandre Borges de FREITAS, 1997, p. 40) no contexto organizacional. Ademais, diante da impossibilidade de separar radicalmente as relações pessoais das relações de mercado (Ciméa BEVILAQUA, 2000), a própria forma de apropriação dos referenciais organizacionais será influenciada por valores e normas profissionais e/ou pessoais dos sujeitos trabalhadores (Régine BERCOT; Anne MAYERE, 2009). Estes tendem a "integrar informações de naturezas diversas na condução de suas práticas cotidianas" (Michel LALLEMENT, 2007, p. 176), inclusive aquelas derivadas da socialização religiosa e de gênero.

A partir de meados do século XX fatores diversos, tais como o aumento do poder de barganha dos trabalhadores, as reivindicações de melhoria nas condições de trabalho ou mesmo a necessidade de explicar variações de desempenho entre os indivíduos, favoreceram mudanças nas técnicas de gestão. Verifica-se a busca de novas fontes de "mobilização ideológica e cultural dos assalariados" (Benoît RAVELEAU, 2002, p.13) que, até então, se baseavam principalmente no estímulo financeiro e/ou nas limitações e constrangimentos de ordem técnica, organizacional ou hierárquica. Emma Bell e Scott Taylor (2004) fornecem diversos exemplos de organizações em que religiosidades ou espiritualidades da Nova Era constituem uma das bases ideológicas da cultura corporativa, apontando também a proliferação de uma literatura que "promove uma visão da organização como um sistema socioespiritual, composto de empregados cujas necessidades existenciais devem ser atendidas se a organização desejar prosperar" (Emma BELL; Scott TAYLOR, 2004, p.65). Destacam, contudo, que alguns autores consideram que a religiosidade "situa-se além dos limites legítimos para a intervenção no ambiente de trabalho, enquanto a espiritualidade é um objeto válido para o interesse organizacional” (Emma BELL; Scott TAYLOR, 2004, p.66). Ali onde uma referência clara à religião poderia causar mal-estar 
ou conflito, a ambiguidade do termo espiritualidade permite a sua utilização em ambientes que se pretendem secularizados, como o ambiente organizacional (Emma BELL; Scott TAYLOR, 2004). Nessa perspectiva, a espiritualidade possibilitaria não se restringir a uma tradição religiosa, fazendo com que "a necessidade de referência ao transcendental se torne obsoleta, salientando-se a natureza imanente dessa relação, baseada no reconhecimento e na realização do ser interior" (Emma BELL; Scott TAYLOR, 2004, p. 66), normalmente mais enfatizada nas religiões orientais. Evidencia-se aí tanto a possibilidade, sempre existente, de que as organizações tenham uma representação da espiritualidade e/ ou das necessidades religiosas de seus/suas funcionários/as, quanto a de procurar instrumentalizá-las para a consecução de seus objetivos empresariais (Emma BELL; Scott TAYLOR, 2004).

Exemplo nesse sentido é a estratégia utilizada pela matriz do Hypermarché na França, conforme pode-se observar em artigo publicado na seção "espaço RH” da sua revista interna, intitulado "Zen, sejamos Zen". O artigo explicita a relação que a empresa supõe haver entre o bem estar pessoal e o desempenho profissional: "porque está provado que colaboradores felizes fazem os clientes felizes, a direção nacional Caixas concebeu uma caixa de ferramentas destinada a favorecer o bem estar das equipes do setor" (Positif!, jul./2010, p. 10). Dos 11 temas da "caixa de ferramentas" ou instrumento pelo qual se pretende promover o bem-estar dos/funcionários/as, apenas três são destacados: "nutrir-se bem, relaxar e se dar prazer". Esses temas, embora aparentemente não possuam vínculo com qualquer religião são, na realidade, contemplados no contexto de algumas formas de espiritualidades contemporâneas que promovem a reinterpretação e combinação de práticas místicas, médicas, alimentares e corporais orientais. A associação com essa forma de espiritualidade contemporânea é estabelecida na revista do Hypermarché por meio das imagens - dentre as quais a de uma muIher praticando yoga - e do título "Zen, sejamos Zen", em referência ao zen budismo. A ideia de um estado "zen" é recuperada na fala de uma assistente de caixa publicada no artigo: "nós estamos mais zen e nós vemos nossa profissão de uma nova maneira" (Positif!, jul./2010, p. 10). O objetivo do recurso a essa forma de espiritualidade é que, en- 
quanto instrumento de "gestão da metafísica individual" (Emma BELL; Scott TAYLOR, 2004, p. 64), ela promova a transformação pessoal e organizacional. Tal expectativa de provocar a transformação pessoal dos/as funcionários/as, resultando em mais profissionalismo, eficácia e diversidade, assim como a de promover transformação organizacional, expressa pela consequente capacidade de "surpreender e encantar" os/ as clientes, transparece no trecho a seguir:

Nós temos um objetivo: surpreender e encantar a cada dia os nossos clientes. As caixas são um lugar privilegiado de trocas e de diálogo onde as assistentes e os assistentes jogam um verdadeiro papel de embaixadores. 'Para lhes permitir bem cumprir essa missão, nós devemos fazer tudo para que eles se sintam bem no seu quotidiano' explica Dominique Girard, responsável nacional Caixas. 'Ainda mais profissionais, eficazes e diferentes, eles saberão encantar nossos clientes' (Positif!, jul./2010, p. 10).

Como parte desse programa, por exemplo, a loja de Sartrouville, na França, inaugurou uma "sala de descontração" destinada às equipes de caixa, às terças e quintas-feiras, e aos/às demais funcionários/as nos demais dias da semana. Nela, são oferecidos conselhos e técnicas de relaxamento, além de massagens aplicadas por uma assistente de caixa (Positif!, jul./2010, p. 15). Podem ser identificados nesse exemplo do Hypermarché França alguns pressupostos da gestão da espiritualidade no trabalho, como apontam Emma Bell e Scott Taylor:

primeiro, envolve o reconhecimento do fato de que os empregados têm uma vida interior relacionada à sua alma e que pode ser acessada por meio de práticas como a meditação, a auto-reflexão (sic) e as preces; segundo, pressupõe que os empregados têm a necessidade de sentir que o trabalho realizado tem sentido; e terceiro, sugere que a organização fornece o contexto ou a comunidade em que ocorre a expressão espiritual (2004, p. 66).

É interessante notar, também no caso da loja de Sartrouville, a forma pela qual, em atitude estimulada pela empresa, uma capacitação adquirida no âmbito pessoal e aparentemente sem vínculo algum com a função exercida - oferecer massagem - é mobilizada para servir a 
um propósito organizacional. Nesse contexto, o uso da espiritualidade pela organização "constitui um aspecto de uma ideologia gerencial mais ampla, que se ocupa com a administração da subjetividade e com a engenharia da alma humana" (Emma BELL; Scott TAYLOR, 2004, p. 73). A mobilização de competências construídas na esfera pessoal transparece também no caso da loja de Bayeux, conforme relatado na revista interna Positif!: uma das "embaixadoras" não apenas preparou a sala de "Bem-estar" - que ela arrumou, pintou e decorou - como também elabora refeições, no âmbito do tema "bem se nutrir" (Positif!, jul./2010, p. 10). Evidencia-se aqui a mobilização de "habilidades adquiridas em casa por meio da socialização para o casamento" (Heleieth SAFFIOTI, 2009, p. 11). Este constitui apenas um dos aspectos pelos quais as representações de gênero e a divisão sexual do trabalho, combinados ou não com elementos do universo religioso, se fazem presentes e/ou são mobilizadas no contexto organizacional, conforme veremos a seguir.

\section{DIVISÃO SEXUAL E DIMENSÕES DO TRABALHO NO SETOR DE SERVIÇOS}

O setor terciário, bastante heterogêneo em termos de atividades e composto por comércio e serviços, é o que tem absorvido o maior contingente de mão de obra feminina. A passagem do modelo fordista ao toyotista, com aumento da automação, terceirização, flexibilização da produção e precarização do emprego figuram entre os fatores que promoveram forte expansão do setor, principalmente a partir da década de 1990. Uma vez que o contato ou o atendimento a clientes constitui o núcleo central das suas atividades, a habilidade interpessoal figura entre as competências requeridas dos/as trabalhadores/as nesse setor. Tal qual na indústria, o trabalho em serviços possui uma dimensão física e cognitiva. Porém, este agrega de forma mais intensa outras dimensões, envolvendo, para além de qualificações mais formais, competências adquiridas no processo de socialização e/ou atributos tidos como subjetivos.

Destacam-se aí a dimensão sexual, que implica na instrumentalização do corpo ou de parte do corpo do/a trabalhador/a na produção do serviço, a dimensão relacional, que implica na capacidade de estabelecer 
e manter a comunicação "guardando o equilíbrio da interação" (Ângelo SOARES, 2002, p. 234), bem como a dimensão emocional, que requer do/a trabalhador/a a compreensão, avaliação e gestão tanto das suas próprias emoções, quanto das emoções dos/as outros/as. Todas essas dimensões estão bem presentes no trabalho das operadoras de caixa do Hypermarché, posto ocupado predominantemente por mulheres.

\section{DIMENSÃO SEXUAL DO TRABALHO}

Um dos aspectos da dimensão sexual do trabalho em caixas de supermercado consiste em que, "para terem acesso a um emprego e para conservá-lo, devem ser atrizes sexualizadas e ter uma apresentação 'atrativa' ou 'agradável”' (Ângelo SOARES, 2002, p. 233). A instrumentalização de atrativos "naturais" femininos tem por alvo os clientes e o objetivo é "atraí-los" ou mesmo "seduzi-los". A aparência atrativa constitui efetivamente uma exigência para o acesso ao posto de operadora de caixa no Hypermarché e pode constituir um fator limitante para mulheres praticantes de algumas religiões. No Hypermarché Brasil, a exigência de uso de maquiagem e brincos constitui empecilho à contratação de mulheres integrantes de igrejas evangélicas ditas "de costumes"3 que não queiram abrir mão dos preceitos religiosos, conforme se verifica nos depoimentos a seguir:

“...Você trabalha com público, quando você tá diretamente com o público, né, e você não pode usar um brinco, não pode passar uma maquiagem, com certeza atrapalha [...] É diferente por exemplo 'olha, vou trabalhar no escritório'. Aí não precisa de maquiagem, não precisa de cabelo preso, não tem problema usar saia. Mas se você vai trabalhar dentro de uma linha de caixa por exemplo, você vai ter que ter uma maquiagem leve, um brinquinho..." (Fernando, coordenador RH Hypermarché Brasil).

O depoimento de Carlos aponta para a dimensão sexual do trabalho:

3 Trata-se de igrejas evangélicas, denominadas "de costumes" por prescreverem o uso de saias e cabelos longos pelas fiéis e thes restringirem o uso de maquiagem e adereços como brincos, de modo que estas são facilmente identificadas pela sua apresentação física. 
“...Eu diria para você trabalhar no caixa a gente exige maquiagem suave, nada de pesado e tal por que... é um cartão de visita da empresa e faz a diferença. [...] 'Ah, mas tem saia no uniforme?' 'Não, não tem. Você vai ter que trabalhar de calça'. E a pessoa desiste da vaga porque ela não, não é permitido pela religião dela, ela chega a perder o emprego..." (Carlos, gerente de caixas Hypermarché Brasil).

A instrumentalização do corpo das operadoras na produção ou até como parte integrante do serviço é expressa pela ideia de que ele "é um cartão de visitas da empresa". No Hypermarché França procura-se igualmente "seduzir" o cliente. A dimensão sexual do trabalho está presente também no contexto francês onde, mesmo não sendo obrigatório, o uso de maquiagem é tido como desejável e a aparência física atrativa permanece como requisito.

A instrumentalização dos atrativos femininos tem também por efeito expor as mulheres ao assédio sexual por parte de clientes, com relatos mais frequentes na unidade francesa do Hypermarché. A operadora de caixa Noemi (Hypermarché França) observa, por exemplo, que investidas por parte de clientes do sexo masculino ocorrem todos os dias. Ela considera que isso é normal, que "eles tentam, pois é um jogo de sedução que existe há muito tempo", mas que, para além disso, há o fato de que, como a profissão de caixa requer "servir ao cliente e ser amável, certos clientes homens vão às vezes muito longe" e pensam que, porque elas Ihes sorriem, Ihes dizem "até logo", elas estariam também interessadas neles. É possível que a baixa incidência de relatos de assédio pelas operadoras de caixas no Hypermarché Brasil deva-se ao fato deste ser visto, no contexto brasileiro mais do que na França, como uma atitude "normal" dos homens. Contudo, ao menos no que se refere ao ambiente interno, ele é sentido também no Brasil. Dalva, gerente comercial de uma das lojas pesquisadas do Hypermarché no Brasil, afirma em seu depoimento que o tempo que as mulheres levam para ascender na empresa é muito maior do que o dos homens, mesmo quando elas são mais competentes do que estes, e considera que isso se deve a preconceitos. Os trechos a seguir dão conta de que o assédio no ambiente interno de trabalho é uma das estratégias de dominação visando a desqualificação das mulheres: 
“...Então assim, pra você se impor como mulher, você também tem, como chefe, como mulher, você tem uma dificuldade maior. Cê tem que impor limites, cortar certos tipos de brincadeira, certos tipos de comentário. Então assim, ah, é...eu vou ser tua amiga, mas sem muito contato, sem muita aproximação pra não confundir. Porque a gente tá muito vulnerável, há muitos comentários, né, então ah, negócio de pôr a mão no ombro de ficar brincando, então você já tem que cortar." (Dalva, Hypermarché Brasil).

Além disso, diversos depoimentos de entrevistado/as da Textile denotam que o assédio constitui uma realidade no ambiente organizacional também no Brasil. Vários dentre eles/as mencionaram, por exemplo, que mulheres pertencentes a religiões de costumes teriam dificuldade de progredir no emprego porque os seus hábitos, em termos de apresentação física e vestimentas (como o porte de saias e cabelos longos), constituiriam um indicador de sua impermeabilidade ao assédio sexual por parte de colegas e/ou de chefes. Isto é, supõe-se que a pertença religiosa, que se faria evidente pela sua apresentação física, indicaria que estas não estariam dispostas a ceder às investidas sexuais de colegas e chefes, em face de prescrições restritivas de sua religião quanto à prática sexual, circunscrita ao casamento. A apreciação de um dos entrevistados, João Pedro, técnico de produção da Textile Brasil, é ilustrativa de alguns dos preconceitos associados à questão do assédio e das estratégias de desqualificação das quais as mulheres são alvo:

"A questão do sexo no ambiente de trabalho, você tem dois casos. Você tem aquela que sofre preconceito por manter aquela retidão "não, comigo não. Isso não", não sei o quê. E cê sabe, tem a muIher que a... né? Ela se, se beneficia desse lado. Esse lado sexy dela. Esse lado da mulher, né, pra conseguir vantagens..." (João Pedro, Textile Brasil).

Observa-se aí a dupla face sexista do assédio no trabalho. A afirmação de que a impermeabilidade ao assédio traria prejuízos à carreira, tem por pressuposto e que a ascensão profissional das mulheres dependeria e/ou resultaria da sua disposição de prestar favor sexual a homens ocupando postos hierarquicamente superiores aos delas. Tal 
ideia é complementada e reforçada pelas insinuações de que algumas delas lançariam mão dos seus atrativos sexuais para ascender profissionalmente, o que se configura como estratégia de desqualificação e de questionamento da competência das mulheres. Na prática, embora possa haver diferença entre a intenção de provocar o assédio e a dimensão sexual do trabalho, esta não deixa de estar apoiada em hierarquias socialmente construídas, que pressupõem ou requerem a disponibilidade sexual das mulheres, reproduzindo assim relações de dominação entre os sexos. Finalmente deve-se destacar que, na medida em que cabe às próprias trabalhadoras gerir o assédio, no sentido de colocar limites às investidas dos clientes e, ao mesmo tempo, evitar que o embaraço gerado resulte em mal estar para estes, a dimensão sexual do trabalho das mulheres no setor de serviços não poderá se efetuar sem agregar competências relacionais e emocionais.

\section{DIMENSÃO RELACIONAL/EMOCIONAL DO TRABALHO}

A dimensão sexual do trabalho no setor de serviços é um dos eixos em torno dos quais a diferenciação intervém segregando e hierarquizando as atividades de acordo com o sexo. Contudo, cada dimensão é inseparável das outras e a naturalização de atributos e/ou habilidades diferenciadas de acordo com o sexo se projeta também sobre as demais dimensões: físicas, cognitivas e emocionais do trabalho. Assim, ocupações que exigem força física, tais quais as de reposição de mercadorias pesadas no Hypermarché ou os postos operacionais na fábrica da Textile, são destinadas aos homens (muito embora certos postos tidos como femininos como, por exemplo, os de operadoras de caixa ou de enfermeiras, também possam requerer força física). Além da força física costuma-se associar tais postos com outros atributos ou comportamentos sociais, tais como a aparência e/ou a forma de se vestir, utilizados como argumentos para justificar a segregação. O contraste entre a forma supostamente "natural" das mulheres se vestirem e aquela considerada adequada ao ambiente da fábrica foi recorrentemente mencionado por entrevistados do sexo masculino como um dos fatores que impediria a presença de mulheres em postos operacionais na Textile. Desde a suposta dificuldade de usar macacões e equipamentos adequados, até 
os saltos altos, tidos como incompatíveis com o paralelepípedo que forma o piso até mesmo da parte externa da área fabril (como se este não pudesse ser mudado e como se os saltos fossem extensões das mulheres), são apresentados como argumentos para remeter e confinar as mulheres à área administrativa da empresa. No Hypermarché, grandes espelhos à entrada da área de funcionários/as procuram otimizar os "atrativos naturais femininos", garantindo que as operadoras de caixa possam verificar se a sua aparência está em conformidade com aquela prescrita pela empresa. No Brasil, o cuidado das operadoras de caixa com a aparência é, por vezes, tão contrastante com a displicência de operadores de loja que chegamos a ter a oportunidade de observar uma delas ironizar um colega, operador de loja, pelo descuido evidente deste com o uniforme e com a aparência pessoal.

As representações de gênero intervêm também sobre a dimensão cognitiva do trabalho, na medida em que se verifica, por exemplo, a associação de atribuições da esfera doméstica - socialmente representadas como femininas - ao desempenho e práticas das mulheres no trabalho. Tal associação pode ser ilustrada pelo caso de uma operadora do setor de alimentos embalados, que, conforme destaca a revista interna "Fique Ligado" do Hypermarché no Brasil (ago./2009, p. 22), prepara os embalados "pensando como consumidora". Ou seja, uma vez que é às mulheres que cabe a responsabilidade de comprar e preparar alimentos, ela integra essa competência, adquirida por meio da socialização de gênero, à sua atividade laboral.

Duas dimensões importantes do trabalho em serviços são a emocional e a relacional. Intimamente ligadas, ambas podem estar eventualmente presentes em algumas das ocupações na área industrial. Contudo, no setor de serviços elas representam o próprio âmago do trabalho (Ângelo SOARES, 2002). Constituem igualmente eixos em torno dos quais a naturalização das diferenças é articulada de modo a estigmatizar ocupações como "femininas" ou "masculinas". Atividades que seriam julgadas pouco interessantes pelos homens, em face da monotonia ou do fato de requererem a permanência num só local durante longo tempo, e/ou ainda aquelas que exigem habilidades ou atributos considerados femininos, são destinadas às mulheres. Esse é 
o caso, por exemplo, da função de secretária, para a qual a paciência seria um atributo necessário, ou de postos administrativos de baixo e médio escalão na Textile, que seriam mais monótonos frente aos postos nas áreas operacionais. E é certamente o caso das operadoras de caixa no Hypermarché, para cuja função a paciência, a gentileza e polidez no trato, além de uma boa apresentação física e o sorriso permanente nos lábios são alguns dos requisitos considerados imprescindíveis.

De fato, os depoimentos dos/as entrevistados/as dão conta de que tais competências são requeridas no exercício da função de operador/a de caixa. Porém, na maioria dos casos, quer no Brasil ou na França, elas não são reconhecidas efetivamente como competências, mas são associadas a atributos "naturais", a habilidades "inatas" das mulheres. Pode-se identificar tal associação no depoimento do gerente Carlos, por exemplo, ao justificar o fato da função de caixa ser ocupada predominantemente ou quase exclusivamente por mulheres:

“... E o homem, ele tem mais receio de trabalhar no caixa é, porque homem é mais explosivo, hã, e o trabalho no caixa exige uma paciência imensa. Um jogo de cintura sem tamanho. Aí eu acredito que o homem ele é essencialmente mais explosivo. Ele não teria paciência, poderia ter mais dificuldade de execução do trabalho, mas eu diria que nessa situação, quer dizer, dessa essência mesmo." (Carlos, Hypermarché Brasil).

Lylia, patinadora na loja do Hypermarché França, relaciona a maior proporção de mulheres no caixa ao fato dos homens não gostarem de ficar parados e de que, na visão dos homens, a capacidade de ser gentil, de repetir sempre a mesma coisa, seria atributo feminino:

“... fazer os movimentos e ficar lá, ser gentil, repetir a mesma coisa... para eles é mais um trabalho de mulheres. Para eles o trabalho de homens é mais nas seções: carregar caixas, colocar as coisas nas prateleiras, puxar os pallets. Para eles isso é mais um trabalho de homem porque ficar no caixa...é verdade que não necessita de força, é ficar sentado todo o dia e passar os artigos. Enquanto eles, os homens, eles gostam bastante de se movimentar, mostrar a sua força, é por isso que nas seções há mais homens que mulheres. E no 
caixa há mais mulheres que homens”4 (Lylia, Hypermarché França).

Por outro lado, depoimentos de entrevistados/as dão conta de que, a partir do momento em que o/a cliente ou o/a caixa se tornam agressivos/as, é ao agente de segurança que cabe resolver a situação. De acordo com Kalil, operador de caixa no Hypermarché França, na loja pesquisada há um agente de segurança para cada duas ou três caixas. É o agente de segurança que vigia o caixa e intervém por si só quando a/o cliente se torna agressivo/a, não sendo preciso que a/o operador/a o chame. Tal fato denota uma atitude de constante vigilância e prontidão, remetendo a um trabalho emocional de tipo diferenciador, isto é, no qual se busca "exprimir a irritação, a desconfiança e a hostilidade a fim de criar um sentimento de mal-estar, de preocupação ou de medo junto ao cliente" (Ângelo SOARES, 2002, p. 237). Verifica-se, portanto, que o trabalho emocional também está sujeito à divisão sexual, de tal modo que tarefas que requerem paciência, "ternura, gentileza, delicadeza, sensibilidade, intuição, doçura, etc.” (Ângelo SOARES, 2002, p. 237), são consideradas mais adequadas às mulheres, enquanto os postos que requerem que as pessoas sejam "agressivas, duras, rudes, frias, etc. [...] em relação àqueles que transgridem as regras" (Ângelo SOARES, 2002, p. 237-238), são destinados aos homens. Assim, se os postos nos caixas do Hypermarché são ocupados principalmente por mulheres, os agentes de segurança são, na maioria, do sexo masculino.

O trabalho das caixas do Hypermarché pode mobilizar competências decorrentes tanto da socialização de gênero quanto da socialização religiosa. Alguns atributos, como o da paciência e o da mansidão, por exemplo, embora não sejam necessariamente tidos pelas religiões aí engajadas como atributos tipicamente "femininos" e/ou a serem cultivados apenas pelas mulheres, são estimulados por certas perspectivas religiosas. Nesse caso, a socialização religiosa e de gênero podem exercer conjuntamente um papel de otimização das competências relacionais/ emocionais requeridas no exercício da função. O caso de Joana é ilustrativo de como a paciência que a atividade de caixa requer pode ser otimizada pela religião:

Tradução livre de depoimento concedido em francês. 
"Eu acho que tem que ter simpatia, né? Ainda brinco assim que tem cliente que a gente tem que dizer "minha simpatia depende da sua" porque você dá bom dia, e "Bom dia por quê? Meu dia não está bom" ou então tem uns que falam assim "À tarde eu te falo se foi bom ou não”. Sabe assim? Então você tem que ter simpatia, junto com a simpatia muita paciência, né? Porque às vezes ele já passou por várias coisas, quando chega no caixa ele vai explodir. Agora eu estou no atendimento. Pior do que o caixa. Porque ele explode lá no caixa, o caixa não pode resolver, manda lá pro atendimento, né. Mas assim, eu acho que tem que ter simpatia, paciência e tentar ser educado o máximo que você pode, sabe? Ter uma educação assim, acima do seu limite porque não é tudo que você ouve que você pode retrucar na hora, você tem que engolir e engolir não é fácil, né? É aí que entra a hora que você fala assim 'Deus me ajuda, me ajuda, porque aquele cliente ali hoje está querendo me tirar do salto e eu não posso descer do salto', então... e aí eu falo com Deus de novo e Ele vai me acalmando, vai me abrandando, entendeu? Porque não é fácil. Às vezes você está calmo, às vezes aparece alguém que tira você do sério totalmente e não pode, né. Você tem que estar, estar sempre ali calminha, sempre... falando manso, sempre, né? E a educação, educação vem de Deus, né? Eu creio que quando uma pessoa tem amor a Deus ela é educada, ela tem uma paciência a mais, ela..." (Joana, entrevistada, Hypermarché Brasil).

Carlos, gerente de caixa de uma das lojas da rede de supermercados, nos fornece outro exemplo de mobilização da religião na gestão do trabalho emocional ao expor a maneira pela qual uma das caixas tratou de gerir as emoções de um cliente:

“E eu já presenciei casos que na loja, né, a menina que eu tenho é muito religiosa, é evangélica. Um dia o cliente chega extremamente irritado e nervoso no caixa dela, né, e ela até pelos ensinamentos que ela tem da igreja e tudo o mais, ela conseguiu filtrar isso desse cliente e fazer com que ele saísse do caixa de uma forma muito mais tranquila, né, muito mais tranquila agradecendo até, muitas vezes." (Carlos, entrevistado, Hypermarché Brasil).

Pode-se observar aqui que há necessidade de avaliar e gerir não apenas as próprias emoções, como também aquelas dos/as clientes, como destaca Ângelo Soares (2002). Esse aspecto do trabalho emocio- 
nal, que contempla a compreensão e avaliação dos sentimentos, tanto dos/as clientes quanto das caixas, é evidenciado por Danièle, gerente adjunta de caixas no Hypermarché França:

“... de fato, de longe, quando vemos o cliente chegar, a gente sente... como tratá-lo. Vamos vê-lo, vai ser preciso falar dessa maneira e não desta. É preciso ser um pouco psicóloga, nesse caso. É preciso ver depois... porque quando vemos um homem ou uma mulher chegando enfurecidos, isto é, após alguns segundos, temos que nos dizer: 'Olha! Para ela, eu vou dizer isso e não isso', para evitar atiçar fogo no combustível. É isso aí!” (Danièle, entrevistada, Hypermarché França).

\section{GESTÃO DAS RELAÇÕES INTERPESSOAIS NO ÂMBITO INTERNO À ORGANIZAÇÃO}

Embora, seja menor do que aquele requerido nas interações com os clientes, portanto pessoas externas à organização, a interação com outros membros da organização em determinadas funções também exige certo nível de gestão das emoções. De acordo com Ângelo Soares (2002), na maioria dos casos a dimensão relacional não está presente no setor industrial, de modo que a gestão das emoções por parte dos sujeitos trabalhadores e da organização se faz, em princípio, menos necessária. Porém, ela não está totalmente ausente. As próprias representações de gênero e religiosas, que estão presentes também aí, parecem evocar a necessidade, imaginada ou real, de gerir relações interpessoais. Essa necessidade imaginada é ilustrada pelo caso de Marcel, diretor de produção na Textile França que, com base num estereótipo das mulheres como "seres psicologicamente fracos, de humor mutável, irracionais, desequilibradas e infantis" (Ângelo SOARES, 2002, p. 238), julga que há uma combinação ideal de homens e mulheres num mesmo ambiente de trabalho, a qual permitiria contornar a tensão que a presença de muitas mulheres tenderia a causar. Segundo ele, tal tensão se deveria à tendência das mulheres, na França, "discutirem muito" e incorporarem muitos "assuntos da sua vida pessoal" ao trabalho, causando conflitos que "duram meses e para os quais é difícil encontrar uma solução", enquanto que, entre os homens, quando há um conflito, este duraria pouco tempo. Ainda na perspectiva de Marcel, a suposta proporção ideal de mulheres entre homens permitiria estimular a performance destes. 
Ademais, determinadas funções, seja na indústria ou no comércio, ainda que não exijam interação com o público externo, contemplam uma dimensão relacional, na medida em que envolvem um maior volume de relações interpessoais e/ou mobilizam um conjunto de competências "associadas ao cuidado e à atenção dispensada ao outro" (Ângelo SOARES, 2002, p. 234). Esse parece ser o caso da função de Marluce, secretária, a qual associa requisitos necessários ao exercício da sua atividade profissional a atributos tidos como "naturalmente" femininos e "inerentes" ao papel de mãe, quais sejam, a paciência e o cuidado:

“É, é eu trabalho numa fábrica de tecidos industriais, então eu sou a secretária do gerente, tá? Só que abaixo do gerente é... temos, 400 e poucas pessoas então, tudo que se refere a essas 400 e poucas pessoas, tem que ser comigo então, a parte do holerit, de tudo, ah, tô precisando disso, é com a Marluce. Tô precisando daquilo, é com a Marluce. É tudo a Marluce, entendeu? Então é... é difícil alguém ter assim, essa coisa de paciência de, né, é muito fácil, né, você falar 'ah, se vira, ah, não sei o que'. Não é assim que se trabalha né? Então quando eu digo paciência de mãe é isso, porque tem dia que cê tá com o saco na Lua mesmo, mesmo em casa com os filhos, e você chega cansada você fala "ah, não tô podendo, né?" Vem eles com os probleminhas você não vai ignorar, né? É a mesma coisa porque é a tua função, né?" (Marluce, Textile Brasil).

A religião também cumpre um papel aí. Mesmo no caso da França, onde a influência do laicismo imprimiu um caráter ilegítimo ou de baixa tolerância à expressão pública da fé religiosa, é possível observar alguns casos de mobilização de referenciais do universo religioso no que diz respeito à gestão das relações interpessoais e/ou do stress no contexto organizacional. Observa-se, porém, neste caso, uma adequação a esse contexto francês mais laicizado: ao invés de uma referência mais explícita à religião, a referência a valores religiosos assimilados a uma "convicção humanista" (Danièle HERVIEU-LÉGER, 1996, p. 22) e/ou àqueles que, embora frequentemente representados como não religiosos, figuram dentro de uma "espiritualidade" de Nova Era (Emma BELL; Scott TAYLOR, 2004). Exemplo deste último caso é o do contramestre da Textile França, Pierre, que, quando perguntado sobre compatibilidades/ 
incompatibilidades e possibilidades de a religião contribuir de alguma maneira no trabalho ou com o trabalho, respondeu negativamente, afirmando que a religião é pessoal, "cabe a cada um crer ou não crer". Contudo, posteriormente evocou valores que ele e sua esposa procuram "inculcar" às suas filhas - "polidez", "respeito pelas pessoas", "saber escutar”, "estender a mão”, “não pensar só em si mesmo”, “pensar nos outros" - e que essas são coisas que devem ser "trabalhadas", que "não caem do céu", "a felicidade se fabrica". A forma de "fabricar" é "desenvolver" o que há de positivo no seu interior, ver as coisas "positivamente", atitude que repercutirá também no ambiente de trabalho, permitindo gerir tanto o stress quanto o sucesso no trabalho:

“...Mas eu acho que todo mundo tem algo em seu interior de positivo e isso se desenvolve, isso se trabalha. Mas é...então a gente crê ou não crê, aí depois...é cada um que... Poderíamos falar durante horas, mas eu acho que isso se trabalha e acho que é no contato com as pessoas, como eu disse agora há pouco, o fato de encontrar pessoas, a gente não encontra as pessoas por acaso..." (Pierre, entrevistado, Textile França).

No trecho a seguir, evidencia-se o papel que Pierre atribui a essa visão para a gestão do stress no trabalho.

“... isso serve para o trabalho, porque o fato de colocar uma barreira, por exemplo: estamos no trabalho, as coisas se passam mal, o cara não está feliz, tudo isso, mas no lugar de 'buumm!' [...] Se você pegar todos os problemas que ele atrai, você vai ficar cansado... No fim do dia, você já imaginou? [...]. É colocar barreiras e atrair só o positivo, colocar barreiras ao negativo. Você verá que o negativo não vai entrar mais. E você não vai ver senão o positivo. É isso que eu creio e é o que nós cremos." (Pierre, entrevistado, Textile França).

O objetivo aí parece ser o de "controlar sua emoção face aos fatos organizacionais 'desestruturantes', que são todos os imperativos de regulação e de racionalização do trabalho suscetíveis de engendrar 'o universo mórbido da falta”' (Brahim LABARI, 2008, p. 216). Ademais tal postura resultaria, segundo ele, numa avaliação positiva e elogiosa do seu trabalho 
No campo brasileiro, pudemos encontrar referências explícitas à relação entre religião e competências de liderança, como no caso de Carlos, por exemplo. Ele considera que a sua religião o ajuda a compreender as pessoas e, portanto, o capacita melhor para o exercício de sua função de gerente de caixas em uma loja da rede de supermercados Hypermarché no Brasil:

\begin{abstract}
"Eu acho que o primeiro ponto é, eles ensinam muito a ouvir. Ouvir bastante. No caso da minha religião ouvir bastante e respeitar as diferenças né, das pessoas. Isso no caso da minha religião eu aprendo muito lá mesmo, inclusive, porque, por exemplo, se um espírita, eu sou médium, tenho incorporação e as pessoas onde eu frequento, $99 \%$ também tem. E dentro desses próprios guias espirituais que a gente incorpora, existe uma divergência muito grande, né. Uma divergência de comportamentos, uma divergência de conhecimentos, né. Mas todos com o intuito comum de crescimento espiritual, de ajudar, né [...] Então tem momentos que você acaba vendo que você precisa um pouco de cada um deles. E eu acabo trazendo isso para o meu dia-a-dia principalmente, profissional, né. Sou líder de cento e poucos funcionários, cada um com um comportamento, cada um com uma história e vida diferenciada, né. E eu acabo trazendo um pouco disso, dos ensinamentos de lá, eu trago para o meu dia-a-dia aqui, no sentido de que eu procuro ver em cada um deles o que tem de melhor." (Carlos, entrevistado, Hypermarché Brasil).
\end{abstract}

Dalva, gerente comercial de uma das lojas do Hypermarché no Brasil, também considera que a sua experiência de participação na igreja católica lhe permite não apenas compreender melhor as pessoas lideradas, como lhe possibilitou desenvolver sua capacidade de expressão e de lidar com as mais variadas situações, resultando em maior domínio e firmeza no exercício de sua função:

“... Eu acho que a religião ela te ajuda a ter um domínio maior pra, por exemplo, falar em público. Se você tem o hábito de ir na igreja, de pregar. Se você tem uma facilidade de... conversar mais com as pessoas, você se torna uma pessoa menos inibida, você tem uma facilidade pra, em algumas situações, você se expor. Expor a tua opinião, a tua vontade. Eu acho que facilita bastante. Porém algumas religiões, te... te trava. Te coloca... na dúvida. Mas a maioria, seja ela 
crente ou católica, se você é praticante, ela te ajuda. Te ajuda a se expressar melhor. A colocar as suas opiniões, a não ter tanto medo de falar em público. Por exemplo, no nosso trabalho hoje, é extremamente necessário falar em público. [...] Ou às vezes vem pessoas da matriz, vem outros diretores, [...] Então... você vê que algumas pessoas, elas não têm preparo e não têm domínio nenhum. [...] Pra ... isto a religião facilita, você ter um domínio maior da oratória, entender, compreender algumas coisas melhor. Se você pratica isso na, na igreja, se você fala em público ou se você questiona, pergunta. Acho que ajuda bastante. Também acredito de, de experiência porque lá você convive com pessoas e tem relatos de experiência de vida, de momentos, de fases, que você vai aprendendo, você vai pegando como experiência. Então, chega em determinadas situações, que você vai se debater, se defrontar com aquilo e você vai lembrar "nossa, uma vez eu lembro que alguém comentou isso, isso e isso e agiu assim". Então te ajuda realmente. Acredito que a religião ela te ajuda a desinibir e a desenvolver algumas habilidades. No caso de falar, de se expressar em público, de entender melhor algumas situações." (Dalva, entrevistada, Hypermarché Brasil).

Mário também estabelece uma influência mútua entre o que aprende no exercício de sua fé religiosa e o exercício da sua função de coordenador de RH no Hypermarché:

“... E aqui usar também o meu conhecimento que eu digo lá na religião... e tentar ajudar a pessoa a, a, a, crescer. Eu mesmo aqui tenho uma equipe de cinco pessoas, né, e eu sei que eles dependem de mim pra muita coisa, né, então assim, eu tenho uma obrigação com essas pessoas de ajudá-los a se desenvolverem, o caminho cada um que vai escolher, mas eu tenho obrigação de mostrar o melhor caminho, que porta que ele vai entrar, ele que vai escolher." (Mário, entrevistado, Hypermarché Brasil).

Os exemplos acima evidenciam que, ao contrário da pretensa impermeabilidade e neutralidade do mundo do trabalho frente à esfera privada e pessoal, esta se faz presente na esfera profissional, revelando ambiguidades e conflitos. A separação entre a esfera pessoal e a esfera do trabalho encontra limites na própria subjetividade do/a trabalhador/a. Até porque o engajamento desta pode se apresentar como instrumento 
útil na busca de soluções para problemas que se colocam no exercício de sua função e/ou na gestão do stress ou mesmo, eventualmente, como meio de fazer frente a déficits de investimento em formação por parte das empresas.

\section{CONCLUSÃO}

Não obstante a ideologia dominante no mundo capitalista moderno ocidental acerca da despersonalização promovida pela estrutura burocrática e da impessoalidade do trabalho, a subjetividade dos/as trabalhadores/ as jamais esteve ausente da sua atividade, nem mesmo sob o taylorismo. Ao contrário, como destaca Danièle Linhart, "ela sempre foi indispensável para dar sentido e operacionalidade a formas prescritas que teriam ficado quase inertes sem a implicação subjetiva e, frequentemente, até mesmo transgressiva dos assalariados, até os mais subalternos" (2008, p. 8-9). Pode-se imaginar a distância entre trabalho prescrito e trabalho real através dos efeitos de greves tartaruga, que não representam nada mais do que "a conformidade às prescrições e normas operacionais" (Danièle LINHART, 2008, p. 9), para aquém de qualquer esforço de interpretação e ou adaptação destas pelos/as trabalhadores/as

O fato os/as próprios/as trabalhadores/as se utilizarem (desde sempre) da estratégia de engajar competências provenientes de experiências pessoais, subjetivas, no exercício da sua função, não significa que as organizações empresariais mantenham uma postura passiva diante dela. Ao contrário, reconhecendo o papel que ela pode jogar, a mobilização da subjetividade dos/as trabalhadores/as passa a ser considerada indispensável para "assegurar a performance das empresas" (Danièle LINHART, 2008, p. 8). Apreendida através daquilo que caracteriza e diferencia um/a trabalhador/a das outras pessoas e dos demais recursos produtivos, ou seja, a "especificidade de suas dimensões cognitivas, de seu registro emocional, afetivo e moral, em conexão também com uma biografia, uma trajetória particular" (Danièle LINHART, 2008, p. 8), a subjetividade passa a ser vista como fator a ser integrado nos métodos e técnicas de gestão.

Da mesma maneira, a fim de atingir os objetivos e fazer face às vicissitudes que se colocam no desenvolvimento de sua atividade, os/ 
as trabalhadores/as podem se ver na contingência de integrar à sua atividade, para além de qualificações/competências obtidas através de programas formais de treinamento e do recurso a técnicas e métodos prescritos, aquelas adquiridas por meio da socialização e/ou práticas desenvolvidas em outras esferas, no âmbito da sua vida pessoal. Inserem-se também aí as competências adquiridas por meio da socialização religiosa e de gênero. Particularmente no contexto da sociedade de serviços, em que as relações interpessoais, as dimensões emocional/ relacional do trabalho, tendem a ganhar em relevância, constituindo a própria "alma do trabalho" (Ângelo SOARES, 2002, p. 230), a socialização religiosa e/ou de gênero tende a fornecer efetivamente um conjunto de competências, sobretudo relacionais.

Observe-se também que os critérios de eficiência, competência, suposta racionalidade econômica, assim como as técnicas/tecnologias, normas, métodos, ou mesmo ritos, festas, formas de sociabilidade, etc., não são neutros, mas decorrem de escolhas que "legitimam o acesso diferencial permanente a chances de vida e apropriação de bens escassos" (Jessé de SOUZA, 2006, p. 39), inclusive de homens, mas principalmente de mulheres. Os horários, turnos e condições de trabalho, as normas quanto à aparência ou quanto às vestimentas, padrões de mobilidade, etc., embora em determinadas situações possam ter relação com fatores de ordem técnica, são estabelecidas também em função de padrões culturais hegemônicos, religiosos, de sexo ou de classe, cuja "naturalização" opera como fator discriminatório, frequentemente invisível.

A naturalização das preocupações domésticas como "femininas", a afirmação de certos atributos - geralmente associados ao seu papel doméstico e de mãe - como essencialmente femininos, bem como a inadequação das mulheres a horários e condições de trabalho tidos como incompatíveis com o seu papel na família, os pressupostos sociais acerca do "corpo feminino" e da sua capacidade de sedução compõem a lista de argumentos em torno dos quais entrevistados/as justificam a adequação/presença e/ou inadequação/ausência das mulheres em determinados postos. A "naturalização" das "competências" e/ou limitações "específicas" de cada sexo como fator determinante de 
postos e funções a ocupar escamoteia o caráter arbitrário do status e valor geralmente superiores que se atribui ao trabalho dos homens em detrimento do das mulheres. Não obstante os padrões organizacionais tendam a reafirmar as representações de gênero e a segmentação de ocupações por sexo, é fato que a socialização de gênero constrói competências, ocasionalmente consideradas superiores às masculinas (Ângelo SOARES, 2002), como ocorre, por exemplo, no caso das caixas de supermercado frente a determinados postos de operadores de loja.

Imposições de ordem religiosa também podem funcionar como limitantes da atuação feminina e/ou contribuir para reforçar estereótipos de gênero. De fato, a socialização em determinadas religiões que valorizam alguns atributos ditos femininos se mostrou relevante no relato de muitos/as entrevistados/as, operando como elemento que favorece e/ ou otimiza a reprodução de representações de gênero. Por outro lado, a participação religiosa pode possibilitar também agregar competências que favorecem a permanência e mesmo a ascensão profissional das mulheres, como, por exemplo, habilidades requeridas no exercício de cargos gerenciais e/ou de direção. Foi possível observar, também, o engajamento de referenciais/perspectivas religiosas na resistência a certas formas de dominação.

Enfim, no mundo contemporâneo as religiões, algumas mais do que as outras, são frequentemente representadas como resquícios de um mundo antigo, fenômeno restrito à esfera privada, à parte da sociedade real. Na prática elas são atravessadas e atravessam o cotidiano, a cultura, o mundo do trabalho, as políticas nacionais e internacionais e, mesmo numa sociedade laicista e muito secularizada como a francesa, a política não passa ao largo da religião; ela tem que ser pensada, medida, gerida. E em todas essas esferas, as religiões permeiam e são permeadas por relações de gênero. Assim, desvelar as entranhas da religião desde uma perspectiva feminista possibilita desnudar as próprias sociedades nas quais os fenômenos religiosos se fazem presentes hoje, nas diversas esferas sociais, quer eles as tomem de assalto, sejam convidados ou sejam tidos como algo a esconjurar. Significa desvelar relações sociais de sexo, de classe, de raça/etnia, coloniais, dentre outras; contemplar facetas de um complexo caleidoscópio de fenômenos 
e relações sociais, as quais têm sido perscrutadas nos diversos artigos e dossiês que a revista Mandrágora tem publicado ao longo do seu já mais de um quarto de século de existência.

Vida longa à Mandrágora!

\section{REFERÊNCIAS BIBLIOGRÁFICAS}

BELL, Emma; TAYLOR, Scott. A exaltação do trabalho: o poder pastoral e a ética do trabalho na Nova Era In: RAE Revista de Administração de Empresas, v. 44, n. 2, São Paulo: EAESP/FGV, 2004, p. 64-78.

BERCOT, Régine; MAYERE, Anne. L'organisation et la communication au sein des systèmes de santé. In: $77^{\circ}$ Congresso Internacional ACFAS. Ottawa, 2009.

BEVILAQUA, Ciméa Barbato. Antropologia e História no mercado de consumo In: SCHWARCZ, Lilia K. Moritz; GOMES, Nilma Lino (Orgs.). Antropologia e História: debate em região de fronteira. Belo Horizonte: Autêntica, 2000, p. 71-91.

FIQUE LIGADO. Carrefour Brasil. Comunicação Interna, ano X, n 69. ago/2009.

FREITAS, Alexandre Borges de. Traços brasileiros para uma análise organizacional. In: MOTTA, Fernando C. Prestes,; CALDAS, Miguel P. (Orgs.). Cultura organizacional e cultura brasileira. São Paulo: Atlas, 1997, p. 38-54

HERVIEU-LÉGER, Danièle. La religion des Européens: modernité, religion, sécularisation In: DAVIE, Grace; HERVIEU-LÉGER, Danièle (Orgs.). Identités religieuses en Europe. Paris: La Découverte, 1996, p. 19-23.

KERGOAT, Danièle. Divisão sexual do trabalho e relações sociais de sexo In: HIRATA, Helena, LABORIE, François, LE DOARÉ, Hélèn, SENOTIER, Danièle (Orgs.). Dicionário Crítico do Feminismo. São Paulo: Editora UNESP, 2009, p. 67-75.

LABARI, Brahim. L'encensement au travail. Référents religieux et profane dans l'expression des subjectivités au travail des ouvrières marocaines. In: LINHART, Danièle (Org.). Pourquoi travaillons-nous ? Une approche sociologique de la subjectivité au travail. Ramonville Saint-Agne: Érès, 2008, p. 211-237.

LALLEMENT, Michel. Le travail. Une sociologie contemporaine. Paris: Gallimard, 2007. LINHART, Danièle (Org.). Pourquoi travaillons-nous ? Une approche sociologique de la subjectivité au travail. Ramonville Saint-Agne: Érès, 2008.

MOTTA, Fernando C. Prestes; CALDAS, Miguel P. (Orgs.). Cultura organizacional e cultura brasileira. São Paulo: Atlas, 1997.

POSITIF!, n 49.Carrefour France. Communication Interne, n 49, jul/2010.

RAVELAU, Benoît. L'individu au travail : antagonismes d'une transformation sociale. Paris: L'Harmattan, 2002.

SAFFIOTI, Heleieth. Novas perspectivas metodológicas de investigação das relações 
de gênero In: SILVA, Maria Aparecida. Seminário Temático II: Mulher em seis tempos. Araraquara: UNESP, 1991, p. 141-176.

SANTOS, Naira Pinheiro dos. Gênero, religião e cultura organizacional: uma perspectiva comparativa entre Brasil e França. São Paulo: Terceira Via; Universidade Metodista de São Paulo, 2018 (Coleção Religião e Estudos Feministas).

SCOTT, Joan. Gênero: uma categoria útil de análise histórica. Educação e Realidade, v. 16, n. 2, , 1990, p. 5-22.

SOARES, Ângelo. Le prix d'un sourire. Travail émotion et santé dans les services In: HARRISSON, Denis, LEGENDRE, Camille (Orgs.). Santé , sécurité \& transformation du travail : réflexions et recherches sur le risque professionel. Québec: Presses de I'Université du Québec, 2002, p. 229-250.

SOUZA, Jessé (org.). A invisibilidade da desigualdade brasileira. Belo Horizonte: UFMG, 2006.

WEBER, Max. A Ética Protestante e o Espírito do Capitalismo. São Paulo: Editora Pioneira, 2000.

Submetido em: 15-9-2021

Aceito em: 22-11-2021

Mandrágora, v.27, n. 2, 2021, p. 209-235 